\title{
REZULTATI KOMPARATIVNOG POKUSA SUNCOKRETA NA LOKACIJAMA KOPRIVNICA I OSIJEK
}

\author{
Tatjana MEĐIMUREC \\ Ministarstvo poljoprivrede - Uprava za stručnu podršku razvoju poljoprivrede i ribarstva \\ Ministry of Agriculture - Directorate for Professional Support to the Development \\ of Agriculture and Fisheries
}

\section{SAŽETAK}

Unazad nekoliko godina, na području sjeverozapadne Hrvatske (Međimurska, Varaždinska i Koprivničko-križevačka županija), povećava se zanimanje poljoprivrednih proizvođača za uzgojem suncokreta. Službenici Ministarstva poljoprivrede su 2020. godine proveli komparativni pokus na dvije lokacije: Koprivnica (Koprivničko-križevačka županija) i Osijek (Osječko-baranjska županija), u kojem je testirano 20 hibrida suncokreta. Cilj istraživanja bio je utvrditi razlike u ostvarenim urodima te fizikalnim i kemijskim svojstvima zrna. U Koprivnici, prosječan urod zrna je bio 3,970 t/ha, hektolitarska masa 43,5 kg/hl, masa 1000 zrna 54,10 g, a sadržaj ulja u suhoj tvari zrna 50,75\%. U odnosu na Koprivnicu, u Osijeku je bio veći prosječan urod zrna $(4,091 \mathrm{t} / \mathrm{ha})$ i sadržaj ulja u suhoj tvari zrna $(51,88 \%)$, a manja hektolitarska masa $(43,4 \mathrm{~kg} / \mathrm{hl})$ i masa $1000 \mathrm{zrna}(52,42 \mathrm{~g})$. Uvjeti za uzgoj suncokreta na ispitivanim lokacijama se znatno razlikuju. Komparativni pokus se planira provesti i u naredne dvije godine s ciljem utvrđivanja adaptabilnosti i stabilnosti testiranih hibrida. Iz ovogodišnjih rezultata može se zaključiti da agroekološki uvjeti u sjeverozapadnoj Hrvatskoj omogućuju uzgoj suncokreta zadovoljavajuće razine uroda i kakvoće zrna.

Ključne riječi: suncokret, urod zrna, hektolitarska masa, masa 1000 zrna, sadržaj ulja

\section{UVOD}

U Republici Hrvatskoj suncokret se uglavnom uzgaja u istočnoj Slavoniji i Baranji gdje postoje povoljni ekološki uvjeti za stabilnu proizvodnju i visoke prinose (Pospišil, 2013.). Vratarić i sur., 2004. navode da je potrebno pomaknuti granicu uzgoja suncokreta na zapadna područja Republike Hrvatske, a to zahtijeva raniji sortiment. U Tablici 1. prikazane su površine zasijane suncokretom u sjeverozapadnom 
Tatjana Međimurec: Rezultati komparativnog pokusa suncokreta na lokacijama Koprivnica i Osijek

dijelu Hrvatske u razdoblju posljednjih šest godina. Podaci o površinama zasijanima suncokretom na području tri sjeverozapadne županije (Međimursku, Varaždinsku i Koprivničko-križevačku) za koje je podnesen zahtjev za potporu tijekom posljednjih šest godina imaju uzlazni trend.

Tablica 1. Površine zasijane suncokretom (ha) za koje je podnesen Zahtjev za potporu na području sjeverozapadne Hrvatske (Međimurska, Varaždinska i Koprivničko-križevačka županija) i na području čitave Republike Hrvatske (RH) u razdoblju 2015.-2020. godine

Table 1 Areas sown with sunflower (ha) for which a Request for support was submitted in the area of northwestern Croatia (Međimurje, Varaždin and Koprivnica-Križevci counties) and in the entire Republic of Croatia (RC) in the period 2015-2020.

\begin{tabular}{lrrrrrr}
\hline Županije / Counties & 2015. & 2016. & 2017. & 2018. & 2019. & 2020. \\
\hline Međimurska & 99,2 & 95,0 & 246,2 & 325,0 & 674,4 & 898,3 \\
Koprivničko-križevačka & 127,1 & 149,9 & 258,9 & 340,7 & 423,6 & 534,2 \\
Varaždinska & 25,7 & 20,0 & 38,9 & 58,9 & 109,2 & 277,9 \\
\hline \multicolumn{1}{c}{ Ukupno u RH } & \multirow{2}{*}{ Total in $R C$} & \multirow{2}{*}{40116,9} & 40193,2 & 42494,2 & 38614,2 & 37909,3 \\
\hline
\end{tabular}

Izvor: Agencija za plaćanja u poljoprivredi, ribarstvu i ruralnom razvoju

Source: Paying Agency for Agriculture, Fisheries and Rural Development

Nekoliko je čimbenika utjecalo na uvođenje suncokreta na oranice sjeverozapadne Hrvatske: mogućnost izbora hibrida suncokreta kraće vegetacije, klimatske promjene, siguran otkup, pad broja stoke (manja potreba za kukuruzom koji je namijenjen hranidbi stoke na vlastitom gospodarstvu), potreba poštivanja uvjeta raznolikosti usjeva i proširenje plodoreda.

Cilj ovog pokusa bio je utvrditi adaptabilnost hibrida suncokreta ranije vegetacije na uvjete proizvodnje u sjeverozapadnoj Hrvatskoj i usporediti ostvareni urod i kvalitetu zrna s lokacijom u Osijeku.

\section{MATERIJAL I METODE RADA}

Na dvije lokacije, na području Republike Hrvatske u 2020. godini, posijan je komparativni pokus suncokreta: u Koprivnici, Bakovčica na površini obiteljskog gospodarstva Kušenić Damira (Koprivničko-križevačka županija) i u Osijeku na pokušalištu Fakulteta agrobiotehničkih znanosti Osijek (Osječko-baranjska županija).

U pokusu je bilo 20 hibrida suncokreta ranije vegetacije, zastupljenih na obje lokacije, od sljedećih distributera sjemena: Syngenta Agro d.o.o., KWS sjeme d.o.o., MAS Seeds, RWA Hrvatska d.o.o., Poljoprivredni institut Osijek i Corteva Agriscience. Od navedenih hibrida, dvanaest hibrida su tzv. clearfield hibridi (IMI) tolerantni na aktivnu tvar imazamoks, a osam hibrida su tolerantni na aktivnu tvar tribenuron-metil (SULFO tehnologija). 
Tatjana Međimurec: Rezultati komparativnog pokusa suncokreta na lokacijama Koprivnica i Osijek

Predkultura suncokretu u Koprivnici je bila pšenica, a u Osijeku kukuruz. Sjetva je u Koprivnici obavljena 17. travnja, a u Osijeku 22. travnja 2020. godine. Žetva u Koprivnici je obavljena 18. rujna, a u Osijeku 10. rujna 2020. godine. Površina obračunske parcele po hibridu u Koprivnici je bila $930 \mathrm{~m}^{2}$, a u Osijeku $454 \mathrm{~m}^{2}$.

$\mathrm{Na}$ lokaciji Koprivnica osnovna gnojidba nije provedena. Predsjetvena gnojidba obavljena je UREA-om u količini od $140 \mathrm{~kg} / \mathrm{ha}$, a startna s $200 \mathrm{~kg} / \mathrm{ha}$ kompleksnog mineralnog NPK gnojiva formulacije 15:15:15. Zaštita usjeva suncokreta (hibridi tolerantni na aktivnu tvar imazamoks) od korova obavljena je u razdvojenoj (split) aplikaciji herbicidom LISTEGO $(0,7+0,5$ 1/ha, aktivna tvar: imazamoks) i herbicidom EXPRESS $50 \mathrm{SX}(25+20 \mathrm{~g} / \mathrm{ha}$, aktivna tvar: tribenuron) za hibride tolerantne na aktivnu tvartr ibenuronmetil. Herbicid FUSILADE FORTE (aktivna tvar: fluazifop-P) u dozi od 1 1/ha korišten je za suzbijanje travnih korova. Tijekom vegetacije je provedena međuredna kultivacija i prihrana KAN-om u količiniod $150 \mathrm{~kg} / \mathrm{ha}$. Obavljena je folijarna prihrana gnojivom Haifa Bonus (13:2:44) u količini od $5 \mathrm{~kg} / \mathrm{ha}$ i zaštita od bolesti u fazi butonizacije fungicidom PICTOR (aktivna tvar: dimoksistrobin i boskalid) u dozi od 0,4 l/ha.

$\mathrm{Na}$ lokaciji Osijek provedena je osnovna gnojidba mineralnim gnojivom PK formulacije 20:30 u količiniod $250 \mathrm{~kg} / \mathrm{ha}$. Predsjetvena gnojidba obavljena je UREAom u količini od $150 \mathrm{~kg} / \mathrm{ha}$, a tijekom vegetacije obavljena je međuredna kultivacija $\mathrm{i}$ prihrana KAN-om u količini od $200 \mathrm{~kg} / \mathrm{ha}$. Zaštita od korova provedena je jednokratno kombinacijom zemljišnih herbicida FRONTIER X2 (aktivna tvar: dimetenamid-p) u dozi od 1,27 1/ha i RACER 25 (aktivna tvar: flurokoridon) u doziod 2,54 1/ha. Zaštita od bolesti provedena je fungicidom PICTORu doziod 0,5 $\mathrm{l} / \mathrm{ha} \mathrm{u}$ fazi butonizacije.

Urod naturalnog zrna u $\mathrm{kg} / \mathrm{ha}$ preračunatog na suho zrno suncokreta (9\% vlage) $\mathrm{i}$ vlaga $u$ žetvi određeni su na pokusnim parcelama prilikom žetve, a mjerenje i određivanje parametara: hektolitarska masa, vlaga zrna, masa 1000 zrna i sadržaj ulja provedeno je u Poljoprivrednom institutu Osijek na uređajima Dickey-John Corporation GAC 200 (Grain Analysis Computer) i MQA 7005 Benchtop NMR (Nuclear Magnetic Resonance) For Oil and Moisture in Oilseed Analysis. Sadržaj nečistoća je također određen u Poljoprivrednom institutu Osijek.

\section{REZULTATI I RASPRAVA}

Agroekološki uvjeti (tlo, voda, temperatura) na dvije lokacije, na kojima je postavljen komparativni pokus, značajno su se razlikovali. Broj dana od sjetve do žetve suncokreta u Koprivnici bio je 155 dana, a u Osijeku 142 dana. Prosječna temperatura zraka za navedeno razdoblje iznosila je $18,7{ }^{\circ} \mathrm{C}$ u Koprivnici, a $20,0{ }^{\circ} \mathrm{C}$ u Osijeku. Ukupna količina oborina za navedeno razdoblje u Koprivnici iznosila je 352,5 mm, a u Osijeku 197,3 mm. Podaci za obje lokacije su preuzeti s CDA stanica Pinova, a u Grafikonu 1. su prikazane količine i raspored oborina tijekom vegetacije suncokreta. 
Tatjana Međimurec: Rezultati komparativnog pokusa suncokreta na lokacijama Koprivnica i Osijek

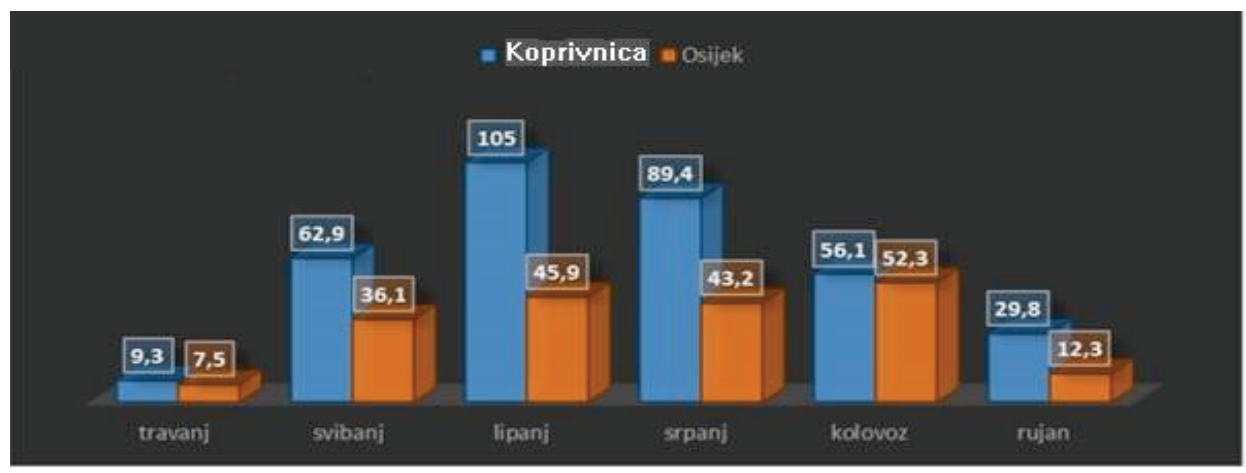

Grafikon 1. Količine (mm) i raspored oborina u Koprivnici i Osijeku tijekom vegetacije suncokreta 2020. godine

Figure 1 Amount and distribution of precipitation $(\mathrm{mm})$ in Koprivnica and Osijek during 2020 sunflower vegetation

Tlo je na navedenim lokacijama bilo različito opskrbljeno makrohranivima i humusom. Rezultati provedene analizetla u Koprivnici su: $\mathrm{pH}$ vrijednost tla 7,1 (KCl), sadržaj humusa $1,7 \%$, sadržaj fosfora je jako nizak, a tlo je srednje opskrbljeno kalijem. Rezultati provedene analize tla za lokaciju Osijek su: pH $(\mathrm{KCl}) 7,27$, sadržaj humusa 2,56\%, sadržaj fosfora - Olsen (mg/kg) 2,60, te sadržaj kalija (AL) (mg/100g) 21,68.

Rezultati provedenog komparativnog pokusa tijekom 2020. godine pokazuju da je prosječni urod suhog zrna suncokreta (9\% vlage) ispitivanih 20 hibrida na lokaciji Koprivnica za $121 \mathrm{~kg} /$ ha manji u odnosu na lokaciju Osijek. Prosječni sadržaj ulja na suhu tvar zrna na lokaciji Koprivnica je za 1,13\% manji u odnosu na lokaciju Osijek. Prosječna masa 1000 zrna veća je u Koprivnici u odnosu na lokaciju Osijek za 1,68 grama. Na lokaciji Koprivnica vegetacija je trajala 13 dana duže u odnosu na lokaciju Osijek. 
Tablica 2. Rezultati pokusa hibrida suncokreta u Koprivnici 2020. godine

Table 2 Experimental results of sunflower hybrids at Koprivnica in the year 2020

\begin{tabular}{|c|c|c|c|c|c|c|c|c|}
\hline \multirow[b]{2}{*}{$\begin{array}{l}\text { Hibrid/ } \\
\text { Hybrid }\end{array}$} & \multicolumn{8}{|c|}{ Koprivnica (Koprivničko-križevačka županija/county) } \\
\hline & $\begin{array}{l}\text { Vlaga u } \\
\text { žetvi } \\
\text { /Harvest } \\
\text { moisture } \\
(\%)\end{array}$ & $\begin{array}{l}\text { Urod } \\
\text { zrna } \\
\text { /Grain } \\
\text { yield } \\
(\mathrm{kg} / \mathrm{ha})\end{array}$ & $\begin{array}{c}\text { Hekto } \\
\text { litarska } \\
\text { masa } \\
\text { /Hecto } \\
\text { Liter } \\
\text { mass } \\
(\mathrm{kg} / \mathrm{hl})\end{array}$ & $\begin{array}{l}\text { Nečisto- } \\
\text { će } \\
\text { /Impuri- } \\
\text { ties } \\
(\%)\end{array}$ & $\begin{array}{l}\text { Masa } \\
1000 \\
\text { zrna/ } \\
\text { Mass of } \\
\text { 1000 } \\
\text { grains } \\
\text { (g) }\end{array}$ & $\begin{array}{c}\text { Vlaga } \\
\text { zrna }{ }^{1 /} \\
\text { Grain } \\
\text { moisture } \\
(\%)\end{array}$ & $\begin{array}{l}\text { Ulje } \\
\text { /Oil } \\
(\%)\end{array}$ & $\begin{array}{c}\mathrm{Ulje} / \mathrm{ST}^{2} \\
/ O i l / D M \\
(\%)\end{array}$ \\
\hline $\begin{array}{l}\text { SY Bacardi } \\
\text { CLP }\end{array}$ & 6,9 & 4285 & 44,3 & 2,19 & 54,95 & 6,1 & 47,85 & 50,96 \\
\hline $\begin{array}{l}\text { KWS } \\
\text { AchillesCLP }\end{array}$ & 8,4 & 4126 & 45,6 & 1,62 & 68,13 & 8,3 & 41,22 & 44,95 \\
\hline MAS 87.IR & 9,1 & 3389 & 44,5 & 2,97 & 46,06 & 6,7 & 49,50 & 53,05 \\
\hline $\begin{array}{l}\text { LG } 50.635 \\
\text { CLP }\end{array}$ & 8,1 & 3638 & 42,6 & 2,19 & 60,49 & 6,1 & 46,57 & 49,60 \\
\hline SY Diamantis & 8,1 & 4581 & 43,1 & 2,45 & 61,44 & 6,5 & 45,95 & 49,14 \\
\hline KWS Acer CL & 6,5 & 3718 & 42,4 & 1,62 & 43,42 & 6,3 & 44,54 & 47,53 \\
\hline $\begin{array}{l}\text { MAS } \\
89 . \text { HOCL }\end{array}$ & 6,2 & 3946 & 43,8 & 1,73 & 56,87 & 5,8 & 45,34 & 48,13 \\
\hline Patricia CL & 6,5 & 3580 & 42,7 & 1,45 & 45,17 & 6,0 & 47,04 & 50,04 \\
\hline Lucia CL Plus & 6,2 & 4266 & 40,5 & 1,46 & 40,15 & 5,7 & 50,56 & 53,62 \\
\hline Driver CL & 5,6 & 3037 & 40,2 & 1,82 & 42,44 & 5,6 & 49,91 & 52,87 \\
\hline Surimi CL & 6,5 & 4181 & 43,8 & 2,46 & 48,59 & 5,5 & 49,47 & 52,35 \\
\hline NK Neoma & 6,5 & 4177 & 45,5 & 1,92 & 48,33 & 5,9 & 48,32 & 51,35 \\
\hline P64LE25 & 8,1 & 4542 & 42,7 & 1,35 & 61,43 & 6,6 & 47,63 & 51,00 \\
\hline P64HE133 & 6,7 & 4076 & 42,7 & 2,25 & 53,26 & 6,0 & 49,11 & 52,24 \\
\hline LG $50.479 \mathrm{SX}$ & 7,1 & 4442 & 44,9 & 2,58 & 55,03 & 6,2 & 47,37 & 50,50 \\
\hline P64HE144 & 7,2 & 4111 & 43,9 & 2,21 & 60,00 & 5,6 & 46,56 & 49,32 \\
\hline P64LE136 & 6,6 & 3009 & 44,3 & 1,76 & 52,46 & 6,0 & 47,51 & 50,54 \\
\hline P64LE99 & 8,0 & 3388 & 44,3 & 2,04 & 66,09 & 6,6 & 48,74 & 52,18 \\
\hline P63LE113 & 8,0 & 4618 & 42,2 & 1,91 & 56,44 & 5,6 & 49,48 & 52,42 \\
\hline Sumiko & 6,4 & 4286 & 45,6 & 1,67 & 61,28 & 5,8 & 50,15 & 53,24 \\
\hline Prosjek/Mean & 7,1 & 3970 & 43,5 & 1,98 & 54,10 & 6,1 & 47,64 & 50,75 \\
\hline
\end{tabular}

${ }^{1}$ Vlaga zrna na dan analize - Grain moisture on the day of analysis

${ }^{2}$ Za izračun sadržaja ulja na suhu tvar (Ulje/ST) uzeta je vlaga zrna na dan analize - For calculation of the oil content on dry matter (Oil / DM) the grain moisture on the day of analysis was taken 
Tatjana Međimurec: Rezultati komparativnog pokusa suncokreta na lokacijama Koprivnica i Osijek

Tablica 3. Rezultatipokusahibridasuncokreta u Osijeku 2020. godine

Table 3 Experimental results of sunflower hybrids at Osijek in the year 2020

\begin{tabular}{|c|c|c|c|c|c|c|c|c|}
\hline \multirow[b]{2}{*}{$\begin{array}{l}\text { Hibrid/ } \\
\text { Hybrid }\end{array}$} & \multicolumn{8}{|c|}{ Osijek (Osječko-baranjska županija/county) } \\
\hline & $\begin{array}{l}\text { Vlaga u } \\
\text { žetvi/ } \\
\text { Harvest } \\
\text { moisture } \\
(\%)\end{array}$ & $\begin{array}{l}\text { Urod } \\
\text { zrna/ } \\
\text { Grain } \\
\text { yield } \\
\text { (kg/ha) }\end{array}$ & $\begin{array}{c}\text { Hektolitars } \\
\text { ka masa } \\
\text { /Hectoliter } \\
\text { mass } \\
(\mathrm{kg} / \mathrm{hl})\end{array}$ & $\begin{array}{c}\text { Nečistoće } \\
\text { Impuri- } \\
\text { ties } \\
(\%)\end{array}$ & $\begin{array}{c}\text { Masa } \\
1000 \\
\text { zrna } \\
\text { /Mass of } \\
\text { 1000 } \\
\text { grains } \\
(\mathrm{g})\end{array}$ & $\begin{array}{c}\text { Vlaga } \\
\text { zrna } \\
\text { /Grain } \\
\text { moisture } \\
(\%)\end{array}$ & $\begin{array}{l}\text { Ulje } \\
\text { /Oil } \\
(\%)\end{array}$ & $\begin{array}{c}\mathrm{Ulje} / \mathrm{ST}^{2} \\
/ O i l / D M \\
\quad(\%)\end{array}$ \\
\hline $\begin{array}{l}\text { SY Bacardi } \\
\text { CLP }\end{array}$ & 8,2 & 4715 & 46,2 & 3,25 & 56,86 & 4,8 & 49,66 & 52,16 \\
\hline $\begin{array}{l}\text { KWS Achilles } \\
\text { CLP }\end{array}$ & 8,4 & 4105 & 43,4 & 3,10 & 64,49 & 4,9 & 43,32 & 45,55 \\
\hline MAS 87.IR & 8,8 & 4485 & 43,0 & 3,46 & 45,33 & 4,6 & 52,54 & 55,07 \\
\hline $\begin{array}{l}\text { LG } 50.635 \\
\text { CLP }\end{array}$ & 11,0 & 4398 & 42,2 & 3,33 & 58,03 & 4,6 & 49,21 & 51,58 \\
\hline SY Diamantis & 8,8 & 4993 & 42,5 & 3,90 & 55,91 & 4,9 & 48,06 & 50,54 \\
\hline $\begin{array}{l}\text { KWS Acer } \\
\text { CL }\end{array}$ & 7,6 & 3581 & 43,5 & 0,95 & 41,52 & 4,9 & 46,42 & 48,81 \\
\hline $\begin{array}{l}\text { MAS } \\
\text { 89.HOCL }\end{array}$ & 9,1 & 4184 & 44,2 & 5,18 & 53,19 & 4,7 & 48,11 & 50,48 \\
\hline Patricia CL & 7,5 & 3406 & 43,8 & 1,06 & 43,71 & 4,6 & 48,79 & 51,14 \\
\hline Lucia CL Plus & 7,7 & 3130 & 38,4 & 3,77 & 37,65 & 4,5 & 51,17 & 53,58 \\
\hline Driver CL & 7,6 & 3380 & 39,1 & 2,67 & 45,32 & 4,4 & 50,94 & 53,28 \\
\hline Surimi CL & 8,2 & 4270 & 46,2 & 3,03 & 51,62 & 4,5 & 51,15 & 53,56 \\
\hline NK Neoma & 8,7 & 4512 & 44,8 & 2,72 & 44,37 & 4,7 & 49,74 & 52,19 \\
\hline P64LE25 & 7,9 & 4150 & 42,3 & 2,24 & 57,60 & 4,8 & 49,50 & 52,00 \\
\hline P64HE133 & 7,9 & 2789 & 43,4 & 8,19 & 53,81 & 4,6 & 49,97 & 52,38 \\
\hline $\begin{array}{l}\text { LG } 50.479 \\
\text { SX }\end{array}$ & 8,8 & 4816 & 46,1 & 2,90 & 52,22 & 4,9 & 48,92 & 51,44 \\
\hline P64HE144 & 8,1 & 3896 & 44,1 & 4,57 & 53,88 & 4,7 & 49,25 & 51,68 \\
\hline P64LE136 & 9,3 & 4219 & 44,1 & 3,74 & 51,34 & 4,6 & 50,34 & 52,77 \\
\hline P64LE99 & 8,7 & 3915 & 43,2 & 2,84 & 62,82 & 4,8 & 49,83 & 52,34 \\
\hline P63LE113 & 7,7 & 4271 & 44,3 & 2,37 & 58,35 & 4,8 & 50,55 & 53,10 \\
\hline Sumiko & 9,2 & 4597 & 43,7 & 2,09 & 60,37 & 4,5 & 51,53 & 53,96 \\
\hline Prosjek/Mean & 8,5 & 4091 & 43,4 & 3,27 & 52,42 & 4,7 & 49,45 & 51,88 \\
\hline
\end{tabular}

${ }^{1}$ Vlaga zrna na dan analize - Grain moisture on the day of analysis

${ }^{2}$ Za izračun sadržaja ulja na suhu tvar (Ulje/ST) uzeta je vlaga zrna na dan analize - For calculation of the oil content on dry matter (Oil / DM) the grain moisture on the day of analysis was taken 
Tatjana Međimurec: Rezultati komparativnog pokusa suncokreta na lokacijama Koprivnica i Osijek

Mijić (2017.) navodi da je u višegodišnjem prosjeku Republika Hrvatska druga zemlja od svih zemalja EU po ostvarenom prosječnom prinosu zrna suncokreta. Usporedimo li prosječne urode zrna suncokreta ostvarene u Republici Hrvatskoj tijekom posljednjih 5 godina (Tablica 4.) s ostvarenim rezultatima komparativnog pokusa provedenog 2020. godine (Tablice 2. i 3.), možemo pretpostaviti da se suncokret može uspješno uzgajati na sjeverozapadnom području Republike Hrvatske. Jukić i sur. (2017.) ukazuju da godina ima veliki utjecaj na prinos ulja po jedinici površine. Krizmanić i sur. (2013.) utvrdili su statistički značajne razlike u sadržaju ulja i sastavu masnih kiselina između godina, lokacija i hibrida. Stoga je važno ponoviti ispitivanje tijekom još barem dvije godine.

Tablica 4. Urod zrna suncokreta u Republici Hrvatskoj (prosjek za sjeverozapadnu, središnju i istočnu Hrvatsku) u razdoblju 2015. - 2019. godina

Table 4 Sunflower grain yield in the Republic of Croatia (average for northwestern, central and eastern Croatia) in the period $2015-2019$

\begin{tabular}{cc}
\hline Godina/Year & Urodzrna/Grain yield $(\mathrm{t} / \mathrm{ha})$ \\
\hline 2015. & 2,7 \\
2016. & 2,7 \\
2017. & 3,1 \\
2018. & 3,0 \\
2019. & 3,0 \\
\hline Prosjek/Mean & 2,9 \\
\hline
\end{tabular}

Izvor: Državni zavod za statistiku

Source: Croatian bureau of statistics

\section{ZAKLJUČAK}

Prosječni urod suhog zrna suncokreta u Koprivnici iznosio je 3,970 t/ha, a u Osijeku 4,091 t/ha. Prosječna vrijednost hektolitarske mase u Koprivnici je iznosila 43,5 kg/hl, a u Osijeku 43,4 kg/hl. Prosječna masa 1000 zrna u Koprivnici je iznosila $54,10 \mathrm{~g}$, a u Osijeku 52,42 g. Prosječan sadržaj ulja u suhoj tvari zrna suncokreta u Koprivnici je iznosio 50,75\%, a u Osijeku 51,88\%.

Rezultati komparativnog pokusa provedenog u 2020. godini pokazuju da agroekološki uvjeti u sjeverozapadnoj Hrvatskoj omogućuju uzgoj zrna suncokreta zadovoljavajuće razine uroda i kakvoće. Ispitivanje se na navedenim lokacijama planira provesti i u naredne dvije godine s ciljem utvrđivanja adaptabilnosti i stabilnosti testiranih hibrida i utvrđivanja statistički opravdanih razlika između ispitivanih lokacija, godina i hibrida. 


\section{RESULTS OF A COMPARATIVE SUNFLOWER FIELD TRIAL AT LOCATIONS KOPRIVNICA AND OSIJEK}

\section{SUMMARY}

In past few years, in the area of northwestern Croatia (Međimurje County, Varaždin County and Koprivnica - Križevci County), the interest of agricultural producers in sunflower cultivation is increasing. In 2020, the Ministry of Agriculture conducted a comparative field on trial with 20 sunflower hybrids at two locations: Koprivnica - Križevci County and Osijek - Baranja County. The aim of the study was to determine the differences in yield and physical and chemical sunflower grain properties. The average yield of sunflower seeds in Osijek was 4,091 t/ha, and in Koprivnica 3,970 $\mathrm{t} / \mathrm{ha}$. The average value of hectolitre mass was 43,4 kg/hl in Osijek, and 43,5 $\mathrm{kg} / \mathrm{hl}$ in Koprivnica. The average weight of 1000 grains was 52,42 $\mathrm{g}$ in Osijek, and 54,10 g in Koprivnica. The average oil content of sunflower grain dry mass was $51,88 \%$ in Osijek, and 50,75\% in Koprivnica. The growing conditions for sunflower differ significantly between the two locations. It is planned to conduct comparative field trial in the next two years to examine the adaptability and stability of the tested hybrids. This year results indicate that agro-environmental conditions in northwestern Croatia are suitable for sunflower production with satisfactory levels of yield and seed quality.

Key words: sunflower, yield, hectolitre mass, 1000-grain weight, oil content

\section{LITERATURA - REFERENCES}

1. Agencija za plaćanja u poljoprivredi, ribarstvu i ruralnom razvoju (2020.), mrežna stranica https://www.apprrr.hr/agronet/

2. Državni zavod za statistiku (2020.), mrežna stranica https://www.dzs.hr/

3. Jukić, G., Mijić, Z., Šunjić, K., Varnica, I., Mijić, Elvira (2017.): Utjecaj lokacije i godine na prinos ulja novijih hibrida suncokreta. Sjemenarstvo, 30(1-2): 5-10.

4. Krizmanić, M., Mijić, A., Liović, I., Sudarić, Aleksandra, Sudar, Rezica, Duvnjak, T., Krizmanić, G., Bilandžić, M. (2013.): Utjecaj okoline na sadržaj ulja i sastav masnih kiselina kod novih OS-hibridnih kombinacija suncokreta. Poljoprivreda, 19(1): 41-47.

5. Mijić,A. (2017.): Hrvatska druga u EU po prinosima suncokreta!, mrežna stranica https://www.agroklub.com/ratarstvo/hrvatska-druga-u-eu-po-prinosima-suncokreta/35836/

6. Pospišil, M. (2013.): Ratarstvo II. dio - industrijsko bilje. Cakovec: Zrinskid.d., str. 13.

7. Vratarić, Marija i suradnici (2004.): Značaj suncokreta kao kulture i proizvodnja suncokreta u svijetu i u Republici Hrvatskoj. U: M. Vratarić (ur.) Suncokret Helianthus annuusL. Osijek: Poljoprivredni institut Osijek, str. 11. 
Tatjana Međimurec: Rezultati komparativnog pokusa suncokreta na lokacijama Koprivnica i Osijek

Adresa autora - Author's address:

mr. sc. Tatjana Međimurec, e-mail: tatjana.medimurec@mps.hr Ministarstvo poljoprivrede,

Uprava za stručnu podršku razvoju poljoprivrede i ribarstva

10010 Buzin, Bani 110

Tel.: 091/4882 777

Fax.: +38514882 700
Primljeno - Received

04.02.2021. 
